Article

\title{
Social Security and Fighting Poverty in Tunisia
}

\author{
Hasna Khemili ${ }^{1}$ and Mounir Belloumi ${ }^{1,2, *(1)}$ \\ 1 Faculty of Economics and Management of Sousse, LAMIDED, University of Sousse, Sousse 4023, Tunisia; \\ akermi_hasna@yahoo.fr \\ 2 College of Administrative Sciences, Najran University, Najran 1998, Saudi Arabia \\ * Correspondence: mounir.balloumi@gmail.com or mrbelloumi@nu.edu.sa; Tel.: +966-530-948-710
}

Received: 21 October 2017; Accepted: 30 January 2018; Published: 19 February 2018

\begin{abstract}
The objective of this study was to examine the role of social security in fighting poverty in Metlaoui, Tunisia, using survey data collected between July 2012 and January 2014, covering 200 poor households. We used questionnaire data, which gave a thorough analysis of the reactions, behavior, and strategies adopted by poor households as a result of various forms of risk. Social security has an effect on a number of different areas, including health, education, housing, and income. Our methodology explored both complete and partial risk-sharing, to investigate the impact of social security schemes on the strategies adopted by households to cope with economic shocks. The estimation results of different models showed that social security could help social security-covered households choose less costly strategies to cope with risks. However, the role of social security remains insufficient, given that covered households had less confidence in its services and they adopted strategies of self-insurance or income smoothing. Overall, the results showed that social security plays an important role in Metlaoui, but it remains insufficient, especially for households that are not covered by social security and are suffering from heavy health expenditures.
\end{abstract}

Keywords: poverty; social security; inequality; shocks; economic growth; Tunisia

JEL Classification: C01; D31; I14; I32

\section{Introduction}

Vulnerability to risk is one of the main causes of poverty. There is broad agreement that social programs reduce poverty and, subsequently, improve the welfare of households in the short term, as well as the long term (Holzmann and Jorgensen 2000).

The Tunisian social security system includes three main categories of interventions against poverty, exclusion, and inequality, and seeks to improve the welfare of households and reduce the consequences of market risks. The Tunisian social security system covers salaried workers against a range of risks, including unemployment. Social schemes can provide assistance and help protect individuals and families from certain contingencies, like being unable to provide for their needs. The level of contribution is not a fixed rate or amount, but varies according to the salary or wage level of each individual. Social schemes come under the umbrella of the Ministry for Social Affairs and Solidarity.

Social security institutions are organized in a network of national, regional, and local bodies. There are two funds under State supervision, in Tunisia, that manage the statutory social security schemes: the National Social Security Fund (CNSS) and the National Pension and Social Contingency Fund (CNRPS). The National Health Insurance Fund (CNAM) manages curative and preventive medical care and supplements both other funds. The National Social Security Fund provides social security for employees and self-employed workers in the private sector, such as agricultural workers, farmers, anglers, domestic workers, and some categories of low-income earners, artists, and 
intellectuals. It covers people against old age, invalidity, death, and unemployment. The National Health Insurance Fund provides cover for social security affiliates in the public and private sectors. It covers medical treatment for sickness, maternity, invalidity, employment accidents, and occupational diseases. The National Pension and Social Contingency Fund provides coverage to civil servants and public sector employees.

The applicable social security schemes differ according to their occupational category. The contribution rate that is paid is not the same for all schemes, but is fixed according to the salary level of each employee. There are two kinds of social security: voluntary and obligatory. Self-employed persons may voluntarily insure themselves against the risks of occupational accidents and occupational diseases. Alternatively, employers may be required to join the CNSS and must declare the employees covered by this fund within a period not exceeding one month from the date of engagement. The scheme is funded by salary contributions. It is levied based on the guaranteed minimum wage, of which two thirds are paid by the employer (between $16.97 \%$ and $20.57 \%$ ) and one third by the employee $(9.18 \%)$. It entitles the covered person to various social services, like health care and a retirement pension.

Indeed, social security in Tunisia should play a key role in protecting employees against the risks of unemployment, sickness, and aging, and contribute to strengthening the human capital and productivity that is necessary for economic growth. Coverage must touch all social categories and groups, including the employed, the unemployed, artists, and intellectuals.

The objective of this study is to investigate and quantify the impact of social security on the vulnerability to risk and poverty in Tunisia. We will attempt to clarify and better understand the impact of social schemes to reduce poverty in Tunisia, using the Metlaoui region as an example.

Our contribution is twofold. Firstly, we will apply the econometric model of Skoufias (2007) to social security schemes in Tunisia, based on health care expenditure as a factor of poverty. Secondly, we will differentiate the effect of income or health expenditure shocks on the risk coping strategies used to finance economic shocks.

This paper is organized as follows. After a brief literature review, the empirical analysis will be described. This analysis will employ data from household surveys, to evaluate the impact of social security schemes on the strategies adopted by households to support themselves during sickness, death, and old age shocks in Tunisia. A considerable portion of the analysis will compare whether there are any differences in the correlation between household income and health care expenditure, between those who are covered by social security schemes and those who are not. We will also investigate how coverage might result in fundamental changes to how households cope with economic shocks. Following an examination of the sensitivity of the results, the last section of this paper will summarize the key findings.

\section{A Brief Literature Review}

In this literature review, we present a selection of studies that have investigated the relationship between poverty and social insurance, the impact of economic, social, and natural shocks on the welfare of households, and the degree of intervention of social schemes after these shocks.

Cochrane (1991) was one of the first to highlight the relationship between social insurance and shocks. This was the first empirical study to address the impact of shocks on household consumption and, subsequently, the social protection effect on the welfare of households. The author sought to find an answer to the following problem: Are households actually insured against idiosyncratic income shocks by formal or informal mechanisms? The results showed that, with perfect insurance, marginal utility should grow at the same rate for all consumers, and that the distribution of the growth rate of consumption must be independent of the shock's variables. The data used in this study covered the period 1981 to 1984 , with a sample size of 2000 to 4000 people. The study concluded that the shock's variables were significantly correlated with the growth rate of consumption. 
Dekker (2004) and Leliveld (2006) showed that illness is a significant risk for people in developing countries. Illness is likely to reduce household income if people are not able to work and cover the costs of treatment. Households often try to pay for medical care by selling productive assets (e.g., land or cattle) or borrowing money. Such strategies increase the risk of becoming trapped in poverty (Scheil-Adlung et al. 2006). Poverty is a topical subject and should, therefore, be a central focus of social programs and future development. Employment is one of the key channels by which economic growth is translated into a reduction in poverty and income inequality (Perry et al. 2006). It is recognized that job creation is one of the most sustainable ways to reduce poverty.

Poverty is a multidimensional phenomenon. The vision of poverty that emerges has so many facets. To highlight this multidimensionality, Handa et al. (2000) tried to combat against relative poverty in rural Mexico by using the national poverty program 'PROGRESA'. They investigated the impact of a social transfer program on the welfare of households. Based on a survey of approximately 24,000 households in 506 villages, Handa et al. (2000) showed that relative poverty increased between March and October (the investigation period), but that this increase was less severe in treatment villages that were eligible for 'PROGRESA' benefits. This was also true for extreme poverty. A decline in poverty leads to a reduction in inequality. This study showed the positive role of a cash transfer program in the reduction of household vulnerability to risk and relative poverty.

Dekker and Wilms (2010) studied the impact of the health insurance program 'Micro Care Insurance', particularly on out-of-pocket (OOP) expenditures. The authors explored the relationship between health insurance and other strategies used to finance medical expenditures and, subsequently, the influence of health insurance on household poverty in Uganda. Survey data were collected from five rural and two urban communities in Uganda in June/July 2006. Insured and uninsured people were chosen randomly to participate, with 259 total observations. To test the relationship between health insurance and OOP health care expenditure, Dekker and Wilms (2010) used ordinary least squares (OLS) regression and a Probit model. They concluded that health insurance was an appropriate instrument to reduce the impact of health risks and an effective poverty reduction strategy in developing countries. Moreover, insured households sold assets less frequently and borrowed less money for the illness than uninsured households. Therefore, the authors adopted the same conclusion as Young et al. (2006), who also found that health insurance helped reduce work incapacity and increase productivity. When households were covered against serious and costly diseases, they had lower OOP health expenditures and were less obliged to use other risk-coping strategies. This resulted in overall improvements to welfare.

Social security is based on the idea of risk-sharing, where many people pay to cover the losses of a few. This idea only works because losses are unpredictable, which means that households, organizations, and governments commonly share risk through transfers and emergency loans. However, most empirical research rejects the predictions of models where insurance is perfect and, instead, show that risk-sharing does not provide full consumption smoothing (Cochrane 1991; Mace 1991; Townsend 1994). Kruse and Ståhlberg (2013) present various welfare programs that alleviate the kind of risks households can encounter, such as not being able to support themselves due to sickness, unemployment, or old age. Residual risk tends to be important. This is especially so in the presence of aggregate shocks, because actors who share idiosyncratic losses are typically simultaneously affected. Therefore, households cannot continue to make transfers between themselves perfectly (Samphantharak and Townsend 2017). Imperfect risk-sharing may arise for different reasons, such as the inability to insure aggregate shocks and limited commitment or information asymmetry (Coate and Ravallion 1993; Attanasio and Pavoni 2011). Anti-selection, as a result of hidden risk information limiting household access to insurance, can also be another reason for insurance market malfunctions. The problems described are the main cause of systematic failures in the complete insurance of affiliates. 


\section{Methodology}

We chose to apply the model established in Skoufias (2007), which is based on a questionnaire and gives a thorough analysis of the reactions, behavior, and strategies adopted by poor households in response to risk. In addition, we chose the Metlaoui region in Tunisia, given that the specialty of this rural region is mining and it is facing very serious shocks following the Tunisian revolution of 2011.

\subsection{Data Sources and Description of Variables}

\subsubsection{Data}

This study used four rounds of panel data from 200 poor households, surveyed to evaluate the impact of Tunisian social security schemes on basic indicators of welfare in Metlaoui. Poor households were classified as those with social security coverage (i.e., CNAM, CNSS, or CNRPS) and those without.

Our choice was not arbitrary, as we chose 200 poor families who needed government help. In Metlaoui, there were almost 600 families receiving government subsidies in 2012. Among these families, some had members who were recruited to the $\mathrm{CPG}^{1}$ in 2013 . We selected 100 of these families and 100 other families who were not employed, in order to obtain a credible evaluation of the potential impact of these schemes. We obtained a list of those persons recruited to the CPG from the Human Resource Management Service.

Furthermore, recent years have been characterized by the violent events that have occurred in Metlaoui between tribal factions. This is likely to have affected household behavior in the region and had a direct impact on the concepts of 'complete' and 'partial' risk-sharing. In this work, we attempt to highlight the effect of these events and their influence on household strategies to mitigate economic shocks.

\subsubsection{Research Survey}

The research survey included 35 questions collecting the socio-economic information required to evaluate the social security schemes. A number of core questions, concerning the demographic composition of households, were asked in each round of the survey. The questions assessed education level, household size, the age, income, and occupation of the head of the household, the total value of household, food, and non-food consumption, and variables characterizing the coping strategies of households to income shocks.

The survey was carried out across four six-monthly periods between July 2012 and January 2014. Descriptive statistics of the main study variables for the poor households covered and not yet covered, are shown in the Table 1.

Consumption, income, and health care expenditure are all expressed as growth rates, while the variables representing shocks and household characteristics are all categorical variables codified as zero or one.

The food consumption value consists of the sum of the value of consumption of fruit and vegetables, cereals and grains, meats and animal products, and other foods. Expenditure on durable goods and other luxury items are included in the calculation of non-food expenditures.

In economics, household income is the income that a household derives from their contribution to economic activity, either directly (e.g., income from work or self-employment) or indirectly (e.g., furniture or real estate investment income). Therefore, we included declared income from work, self-employment, pension, interest, rents, community profits, and government transfers.

Health expenditure, as defined by the World Bank, represent the total of public and private health expenditure. This includes the delivery of health services (preventive and curative), family planning

1 CPG is a Tunisian phosphate company based in the governorate of Gafsa in Tunisia. 
activities, activities related to nutrition, and health emergency services. In this study, household health expenditure included expenditure on health care and services (hospital care, outpatient care, medical transportation, and medical goods), as well as preventive medicine.

The variables identifying the various shocks experienced by households were acquired by direct questions. In each survey, households were asked if, during the last six months, they had experienced a drought, fire, flood, serious illness, or accident, and if, because of these shocks, they had lost their land, crops, animals, houses, or other items. Finally, they were asked how they responded to these shocks, for example, by selling land, selling household items, selling animals, receiving money from the government, borrowing money, getting additional work, and/or receiving help from family members. ${ }^{2}$

Table 1. Descriptive Statistics.

\begin{tabular}{|c|c|c|c|c|c|}
\hline \multirow{2}{*}{ Variables } & \multirow{2}{*}{ Description of Variables } & \multicolumn{2}{|c|}{ Covered Households } & \multicolumn{2}{|c|}{ Non-Covered Households } \\
\hline & & Mean & SD & Mean & SD \\
\hline $\mathrm{TC}$ & Total consumption per month (TND) ${ }^{1}$ & 366.703 & 141.993 & 282.778 & 65.557 \\
\hline FC & Food consumption per month (TND) & 229.929 & 81.468 & 176.631 & 52.549 \\
\hline NFC & Non-food consumption per month (TND) & 136.773 & 82.681 & 106.147 & 44.067 \\
\hline $\mathrm{R}$ & Income per month (TND) & 464.432 & 184.093 & 325.691 & 76.482 \\
\hline $\mathrm{HC}$ & Health care expenditure per month (TND) & 74.361 & 111.038 & 142.251 & 123.194 \\
\hline LH & Loss of harvest & 0.093 & 0.29 & 0.096 & 0.295 \\
\hline DLH & Death, or loss of house & 0.07 & 0.26 & 0.083 & 0.276 \\
\hline IM & Injury of a household member & 0.166 & 0.37 & 0.156 & 0.364 \\
\hline $\mathrm{LO}$ & Loss of articles or other items & 0.116 & 0.32 & 0.11 & 0.313 \\
\hline $\mathrm{HH}$ & Gender of the head of household & 0.086 & 0.281 & 0.07 & 0.255 \\
\hline $\mathrm{AH}$ & Age of the head of household $>50$ (years) & 0.246 & 0.431 & 0.173 & 0.379 \\
\hline ED & Education $<$ primary & 0.11 & 0.313 & 0.22 & 0.414 \\
\hline \multirow[t]{2}{*}{ LOD } & Lodgment & 0.583 & 0.493 & 0.073 & 0.261 \\
\hline & \multicolumn{5}{|c|}{ How they responded to these shocks? } \\
\hline $\mathrm{BM}$ & Borrowed money & 0.2 & 0.4 & 0.12 & 0.68 \\
\hline SA & Sold animals & 0.13 & 0.34 & 0.09 & 0.29 \\
\hline $\mathrm{SH}$ & Sold house or other item(s) & 0.15 & 0.36 & 0.13 & 0.34 \\
\hline RF & Received help from family & 0.19 & 0.39 & 0.2 & 0.4 \\
\hline RG & Received help from the government & 0.093 & 0.28 & 0.22 & 0.41 \\
\hline WM & Worked more & 0.22 & 0.41 & 0.176 & 0.382 \\
\hline
\end{tabular}

${ }^{1}$ TND: Tunisian Dinar.

\subsection{Method}

There are diverse strategies to insure against idiosyncratic risks. Rosenzweig and Wolpin (1993) reported that households might be forced to sell assets when they face shocks. For example, livestock transactions can smooth income fluctuations (Fafchamps and Pender 1997; Fafchamps et al. 1998). Self-insurance is one of the most effective approaches to risk-coping (Lim and Townsend 1998).

\subsubsection{Complete Risk-Sharing}

Mace (1991) and Hayashi et al. (1996) assumed that, within a complete market, there is complete risk-sharing. This means that income fluctuations should not have a significant impact on the consumption of households.

We begin our empirical analysis by investigating the impact of social security schemes on the strategies adopted by households to cope with shocks in Tunisia. According to the standard theory of complete risk-sharing, Townsend (1995), Mace (1991), and Cochrane (1991), showed that GDP fluctuations should not play an important role in explaining country-level changes in consumption. In poor countries, social security is weak or non-existent and risks are frequently present, particularly

2 Some variables (such as family size and head of family) were not included in the analysis due to their strong collinearity with the other variables. 
the risk of unemployment, sickness, death, and adverse weather. For these reasons, social assistance between households is crucial for poor households. Alderman and Paxson (1992) distinguish that two of the strategies that are often adopted to cope with risks are self-insurance and risk-sharing. This model is based on a consumer optimization problem, within the context of a complete market (Deaton 1992). This concept allows households to protect themselves against risks. The assumption of this model is that the growth rate of household consumption between $t$ and $t-1$ will be a function of the growth rate of shocks affecting the community. Therefore, Equation (1) is the more commonly encountered equation in the literature. The formal tests for risk-sharing, presented in Townsend (1994, 1995), Cochrane (1991), and Mace (1991), exploit the fact that the growth rate of household consumption within an insured community, between periods $t-1$ and $t$, will only be a function of the growth rate in aggregate shocks affecting the community. Equation (1) summarizes the full risk-sharing hypothesis:

$$
\Delta L n C_{h t}=\alpha+\beta \Delta \ln R_{h t}+\phi X_{h t}+\Delta \varepsilon_{h t}
$$

where $\Delta L n C_{h t}$ is the growth rate of total consumption per capita of household $h$, at period $t ; \Delta \ln R_{h t}$ is the growth rate of income; $X$ is a vector of the characteristics of the head of the household (i.e., whether the head of the household is a female, has a low level of education, has a lodgment, and is more than 50 years old); $\alpha, \beta$, and $\phi$ are the parameters to be estimated; and $\varepsilon_{h t}$ represents a household-specific error term.

Equation (1) represents the relationship between the consumption growth rate, $C$, and the income growth rate, $R$. The parameter, $\beta$, provides an estimate of the extent to which income changes play a significant role in explaining the household consumption growth rate. It indicates the partial correlation between income and consumption for non-covered households. If $\beta=0$, there is complete risk-sharing (Townsend 1994; Mace 1991; Jacoby and Skoufias 1998), while if $\beta=1$, this implies a total absence of any risk-sharing. For a low income coefficient that is close to 0 , the full risk-sharing hypothesis is rejected, which implies that the growth rate of consumption is related to the growth rate of income. Therefore, we test the hypothesis of partial risk-sharing.

According to Amin et al. (2003), a high (low) estimated value of $\beta$ means that as the degree of consumption insurance decreases (increases) and there is a higher (lower) vulnerability of consumption to income risk. In order to verify the complete risk-sharing hypothesis in a country, Skoufias (2007) estimated a modified version of Equation (1), by which he tried to estimate risk-sharing for the poor who were covered and not yet covered by transfer programs (Equation (2)). Skoufias (2007) investigated the impact of social insurance schemes on vulnerability to risk for covered households. For this, the growth rate of consumption was set as a function of the growth rate of income for covered and non-covered households by including the binary variable, cot, as follows:

$$
\Delta L n C_{h t}=\alpha+\beta \Delta L n\left(R_{h t}\right)+\cot \left(\gamma_{p}+\beta_{p} \Delta \ln \left(R_{h t}\right)\right)+\phi X_{h t}+\Delta \varepsilon_{h t}
$$

where cot is a binary variable taking the value of 1 for a covered household or 0 for a non-covered household; $\alpha, \beta, \beta_{p}$, and $\phi$ are the parameters to be estimated; and $\varepsilon_{h t}$ represents a household specific error term.

According to Heckman et al. (1999), the coefficient $\beta_{p}$ is the difference in vulnerability to risk between covered and non-covered households. If $\beta_{p}$ is negative, this implies that social security is associated with a decreased vulnerability to risk for the covered households.

Therefore, there would be complete risk-sharing for non-covered households if $\beta$ is positive and significant; whereas, if $\beta_{p}$ is significantly negative this would suggest that Tunisian social security reduces the impact of income risks faced by households. We have documented that health care expenditure has dramatic implications for household welfare. The aim of our analysis is to highlight the impact of social health insurance on the welfare of households. To focus on our contribution, which 
is the impact of health care expenditure risk on household poverty, we adopt a different version of Skoufias's model (2007). Our model becomes:

$$
\Delta \operatorname{Ln} C_{h t}=\alpha+\beta \Delta \operatorname{Ln}\left(R_{h t}\right)+\beta^{\prime} \Delta L n\left(D S_{h t}\right)+\cot \left(\gamma_{p}+\beta_{p} \Delta \ln \left(R_{h t}\right)+\beta_{p}^{\prime} \Delta L n\left(D S_{h t}\right)\right)+\phi X_{h t}+\Delta \varepsilon_{h t}
$$

where $\Delta \ln D S_{h t}$ is the growth rate of health care expenditure of household $h$, at period $t ; \alpha, \beta, \beta^{\prime}, \beta_{p}$, $\beta^{\prime}{ }_{p}$, and $\phi$ are the parameters to be estimated; and $\varepsilon_{h t}$ represents a household specific error term.

The extent to which households are able to insure their consumption against shocks that affect their income, may be determined by the parameter $\beta$, and for health expenditure, by $\beta^{\prime}$.

\subsubsection{Partial Risk-Sharing}

Altug and Miller (1990), Mace (1991), Townsend (1994), and Attanasio and Davis (1996), all indicate that there is a degree of partial insurance even if the hypothesis of complete insurance is, in general, rejected. They have shown that the assumption of a complete market is rejected in the case of market imperfections and that there is a certain degree of risk-sharing. A large body of empirical research has referred to partial risk-sharing (Altug and Miller 1990; Cochrane 1991; Nelson 1994; Attanasio and Davis 1996). When household incomes vary widely over time, there is at least partial risk-sharing. In the case of Tunisian rural areas, partial risk-sharing prevails. For developing countries and rural areas, Townsend (1994) tried to verify the hypothesis of 'perfect insurance' or full risk-sharing using utility in an exponential form, with data from Indian villages. Using the 'food consumption' variable, he showed that the assumption of complete risk-sharing is rejected. Dercon and Krishnan (2000) have also shown that shocks are not perfectly insured within households. Similarly, based on U.S. data, Cochrane (1991) showed that a simultaneous decrease in both consumption and income could be interpreted as a rejection of complete risk-sharing.

In order to determine if partial insurance and risk-sharing are taking place among households, we estimated an alternative version of Equation (3), as suggested by Deaton (1997) and Ravallion and Chaudhuri (1997). In this equation, the consumption growth rate is explained by the growth rate of household income and health care expenditure.

Ravallion and Chaudhuri (1997) suggest that the growth rate of average income has a significant role in the growth rate of household consumption $(\gamma \neq 0)$. This implies that some risk-sharing is taking place within non-covered households. We adopt this approach in the following model:

$$
\begin{aligned}
& \Delta \ln C_{h t}=\alpha+\beta \Delta \ln R_{h t}+\beta^{\prime} \Delta \ln D S_{h t}+\gamma \Delta\left(\overline{\ln R_{h t}}\right)+\delta \Delta\left(\overline{\ln D S_{h t}}\right)+\cot \left(\alpha_{p}+\beta_{p} \Delta \ln R_{h t}\right. \\
& \left.+\beta_{p}^{\prime} \Delta \ln D S_{h t}+\gamma_{p} \Delta\left(\overline{\ln R_{h t}}\right)+\delta_{p} \Delta\left(\overline{\ln D S_{h t}}\right)\right)+\phi X_{h t}+\Delta \varepsilon_{h t}
\end{aligned}
$$

where $\Delta \overline{\ln R_{h t}}$ is the growth rate of average income; $\Delta \overline{\ln D S_{t}}$ is the growth rate of average health expenditure; and $\alpha, \alpha_{p}, \beta, \beta_{p}, \beta^{\prime}, \beta_{p}^{\prime}, \phi, \gamma, \gamma_{p}, \delta$ and $\delta_{p}$ are the parameters to be estimated.

\subsubsection{Vulnerability by Characteristics}

In this section, we estimate the impact of economic shocks by pooling together different types of households. Table 1 provides an overall estimate of the vulnerability to risks of households of different characteristics. However, these estimates can hide some information on the level of vulnerability to risk and the degree of risk-sharing between households. The potential effect of social security on the reduction in vulnerability to risk can be more or less apparent for households who have the same characteristics. To investigate this point, we re-estimated Equation (3) using a sub-sample of households with the same characteristics, including whether the head of the household is a female, the level of education is less than or equal to primary school, age is greater than 50 years, and the household has a house, as follows:

$$
\Delta \operatorname{Ln} C_{h t}=\alpha+\beta \Delta \operatorname{Ln}\left(R_{h t}\right)+\beta^{\prime} \Delta \operatorname{Ln}\left(D S_{h t}\right)+\Gamma\left(\gamma_{p}+\beta_{p} \Delta \ln \left(R_{h t}\right)+\beta_{p}^{\prime} \Delta \operatorname{Ln}\left(D S_{h t}\right)\right)+\phi X_{h t}+\Delta \varepsilon_{h t}
$$


where $\Gamma$ is a binary variable identifying if the household is covered or not yet covered by social security. The signs $\beta$ and $\beta^{\prime}$ identify the relationship between income, health care expenditure, and consumption within the group of households with the same characteristic (i.e., $Z=1$ ) for non-covered households; while, $\beta_{p}$ and $\beta_{p}^{\prime}$ indicate whether covered households with the same characteristic, $Z$, are more or less covered than comparable other households.

\subsubsection{Shocks of Material Risks and Their Impact on the Strategic Choices of Coverage}

Based on this analysis, we try to show the impact of shocks for those who are not covered and if the same shock has the same effect on a covered household. These impacts are represented by $\beta, \beta^{\prime}, \beta_{p}$ and $\beta_{p}^{\prime}$. We estimate a Probit model in order to highlight the intervention of social security in the case of a shock. Our sample is, therefore, divided into two sub-groups (covered and not covered). To know the nature of household responses, we make some comparisons between the two sub-groups. If the reactions to risk are different, this can be interpreted as importance of the social security intervention in covering households from potential risks.

Among the strategies outlined in the literature, some households respond to risk by depleting household assets, for example, through the sale of a house (Rosenzweig and Wolpin 1993). There can also be labor supply adjustments (Kochar 1998) and the utilization of other strategies that mean poor households must withdraw their children from school (Jacoby and Skoufias 1997). Morduch (1994) showed that households could avoid taking risks by practicing income smoothing and, subsequently, consumption smoothing. Because of these actions of self-insurance, households will be less vulnerable to risks; however, their vulnerability to future poverty could increase.

We estimate the Probit model of Skoufias (2007). This approach is similar to that used for consumption. We used a number of binary variables, signifying yes or no responses to questions or actions, and examined whether the incidence of these shocks was associated with an increased likelihood of these actions, using the following model:

$$
P\left(Y_{i}=1\right)=F\left(\alpha+\beta S_{i}+\cot \left(\alpha_{p}+\beta_{p} S_{i}\right)+\varphi X_{t}\right.
$$

where $F$ is the cumulative normal distribution and the variable $Y$ denotes any one of the following responses: (i) the household sells animals; (ii) they borrow money; (iii) they receive government help; (iv) household members work more; (v) they receive help from family members; and (vi) they sell other items. $S$ represents a vector of dummy variables that indicate the impact of any of following shocks: (i) loss of harvest; (ii) death of a family member or loss of a house; (iii) injury of a family member; and (iv) loss of items or furniture. The variable $X$ represents a vector of household characteristics (i.e., whether the head of the household is a female, the level of education is less than or equal to primary school, age is greater than 50 years, and the household has a lodgment).

We investigate, here, whether the impact of a shock increases the probability that the dependent variable, $Y$, is equal to 1 for a non-covered household, and if the impact of the same shock causes a reaction that is more or less strong for a covered household (summarized by $\beta_{p}$ ).

\subsubsection{Review of the Sensitivity of the Results}

The purpose of this step is to examine the sensitivity of the results, by introducing instrumental variables in Equation (3), which are the variable 'shocks' or risks (i.e., loss of harvest, death of a family member or loss of a house, injury of a family member, and loss of items or furniture).

The OLS estimates may be biased because of measurement error of the income variable and errors in the calculation of food and non-food consumption and health care expenditure. Deaton (1997) showed that there is a possibility that income coefficients are biased and that there is a lower bound estimate of the true elasticity of consumption to income. 


\subsubsection{The Direct Impact of Shocks on Consumption Variables}

The last step consists in examining the impact of shocks on consumption variables. In order to take into account measurement error in income and consumption and biased estimates, Skoufias (2007) make use of another sensitivity test. In this case, we examine risk-sharing using the shock variables instead of income:

$$
\Delta \ln C_{i t}=\alpha+\beta S_{i t}+\cot \left(\beta S_{i t}\right)+\varphi X_{i t}+\Delta \xi_{i t}
$$

where $S$ is a vector denoting the incidence of household shocks between $t$ and $t-1$. As in Equation (3), under the null hypothesis of complete risk-sharing $(\beta=0)$, the shocks should have no effect on the household consumption growth rate.

\section{Results and Discussion}

We begin, firstly, by applying the Fisher test of homogeneity to check whether there is a specific effect. It is clear from the result of the Fisher test (probability $P=1>0.05$ ) that there is no specific effect. Therefore, the households in our sample are homogeneous. This result is expected because all households are residents of the same region (Metlaoui). They also have the same socio-professional category and are listed on the same social security fund. Therefore, we have a Pooled Panel model. Next, we check the complete risk-sharing hypothesis ${ }^{3}$.

The only way to test this hypothesis is to examine whether the growth rate of food consumption is independent of the growth rate of income and health expenditure. The OLS estimates of Equation (3) for total consumption and for food and non-food consumption are presented in Table 2.

Table 2. OLS estimation of complete risk-sharing (Equation (3)).

\begin{tabular}{|c|c|c|c|c|c|c|c|}
\hline \multirow{2}{*}{ Types of Households } & \multirow{2}{*}{ Independent Variables } & \multicolumn{2}{|c|}{ In (Total Consumption) } & \multicolumn{2}{|c|}{ In (Food Consumption) } & \multicolumn{2}{|c|}{ ln (Non-Food Consumption) } \\
\hline & & Coefficient & $t$-Value & Coefficient & $t$-Value & Coefficient & $t$-Value \\
\hline $\begin{array}{l}\text { Households not covered } \\
\text { by social security }\end{array}$ & Income & $0.8009^{* * *}$ & 10.75 & $0.8002^{* * *}$ & 6.97 & $1.342^{* * *}$ & 4.42 \\
\hline \multirow{2}{*}{$\begin{array}{l}\text { Households covered by } \\
\text { social security }\end{array}$} & Income & -0.113 & -1.21 & $-0.256^{* * *}$ & -1.87 & -0.802 & 1.45 \\
\hline & Health care expenditure & 0.0011 & 0.11 & 0.0083 & 0.66 & -0.0381 & -0.86 \\
\hline \multirow{2}{*}{$\begin{array}{l}\text { X: characteristic } \\
\text { variables }\end{array}$} & Head of household is female & 0.0053 & 1.83 & -0.0004 & -0.1 & 0.013 & 0.73 \\
\hline & Household has a lodgment & 0.0051 & 1.40 & -0.0001 & -0.02 & 0.038 & 2.47 \\
\hline
\end{tabular}

Notes: The $t$-values reported are determined using the Huber-White test. ${ }^{* * *}$ shows significance at the $1 \%$ level.

The significant coefficients of $\beta$ reveal that neither total consumption nor the two main components of consumption (food and non-food consumption) are completely insured against income shocks. For example, for those who were not covered, a 10\% decrease in income was associated with an $80 \%$ decrease in total household consumption. The same decrease in income was also associated with an $80 \%$ decrease in food consumption and a $134 \%$ decrease in non-food consumption.

The coefficient of non-food consumption was higher than the coefficient of food consumption, suggesting that consumption of food can be better insured than the consumption of non-food. This difference can be explained by assumptions of household preferences. An increase in household income will increase the requested quantity of products like buildings, transport, internet, and other luxury, non-food products. As shown above, there is a strong indication that the differences in the coefficients may be attributed to a lack of insurance rather than a change in preferences.

The coefficients of health expenditure, for those who were covered and not covered $\left(\beta^{\prime}\right.$ and $\left.\beta^{\prime} p\right)$, were not significant. Therefore, health care expenditure for those who were covered and not covered by social security had no effect on the total consumption of households or food or non-food consumption,

3 We checked the autocorrelation and heteroscedasticity before running regressions. 
which suggests that there were no significant differences in the level of consumption insurance between the two groups of households in response to risk (e.g., long term illness, accident, or chronic disease). Our analysis confirms the result of Cochrane (1991), which rejects the complete insurance of some idiosyncratic shocks, like long-term illness. The larger effect for those not covered is explained by a lower degree of consumption insurance and, thus, a higher vulnerability to income risk. However, for those being covered, there is a higher degree of consumption insurance and a lower vulnerability to income risk. Social security is associated with a decreased vulnerability to risk for covered households. Households that are covered by social security are insured against sickness, death, and old age.

The negative estimate of $\beta_{p}$ implies that social security is associated with a decreased vulnerability to risk for covered households. We find that the coefficients of income, for covered households, are not significant for total consumption and non-food consumption, suggesting that there are no significant differences in the level of consumption insurance between covered and non-covered households after the initiation of these schemes. This result aligns with the result of Garcia-Verdu (2002). However, it should be noted that this finding does not necessarily imply that social security in Tunisia has no impact on consumption insurance level for covered households.

The significant coefficient of food consumption, for covered households, is negative. This shows that social security reduces income risks of and minimizes exposure to risk for people who are covered.

Following these results, we can say that there is not complete risk-sharing between non-covered households. This result is not final because we have not yet tested the partial risk-sharing scale in the second model, where we introduce average income and average health care expenditure. The OLS estimates of Equation (4) are reported in Table 3.

Table 3. OLS estimation of partial risk-sharing (Equation (4)).

\begin{tabular}{|c|c|c|c|c|c|c|c|}
\hline \multirow{2}{*}{ Type of Households } & \multirow{2}{*}{ Independent Variables } & \multicolumn{2}{|c|}{$\begin{array}{c}\ln \text { (Total } \\
\text { Consumption) }\end{array}$} & \multicolumn{2}{|c|}{$\begin{array}{c}\ln (\text { Food } \\
\text { Consumption) }\end{array}$} & \multicolumn{2}{|c|}{$\begin{array}{l}\ln \text { (Non-Food } \\
\text { Consumption) }\end{array}$} \\
\hline & & Coefficient & $t$-Value & Coefficient & $t$-Value & Coefficient & $t$-Value \\
\hline \multirow{2}{*}{$\begin{array}{l}\text { Households not covered } \\
\text { by social security }\end{array}$} & Mean income $(\hat{\gamma})$ & -0.0385 & -0.15 & -0.662 & -1.73 & $2.124 * * *$ & 1.83 \\
\hline & $\begin{array}{l}\text { Mean health care } \\
\text { expenditure }(\hat{\delta})\end{array}$ & -0.049 & -0.6 & -0.099 & -0.66 & 0.279 & 0.87 \\
\hline \multirow{2}{*}{$\begin{array}{l}\text { Households covered by } \\
\text { social security }\end{array}$} & Mean income $(\hat{\gamma p})$ & 0.278 & 1.02 & 0.733 & 1.48 & -1.23 & -0.95 \\
\hline & $\begin{array}{l}\text { Mean health care } \\
\text { expenditure }(\hat{\delta} p)\end{array}$ & -0.0094 & -0.10 & 0.0986 & 0.60 & -0.426 & -1.19 \\
\hline \multirow{4}{*}{$\begin{array}{l}\text { X: characteristic } \\
\text { variables }\end{array}$} & Head of household is female & 0.005 & 1.34 & -0.0005 & -0.11 & 0.013 & 0.74 \\
\hline & Age is over 50 years & 0.001 & 0.35 & 0.006 & 1.61 & -0.015 & -1.20 \\
\hline & $\begin{array}{l}\text { Education is less than } \\
\text { primary school }\end{array}$ & 0.001 & 0.37 & 0.002 & 0.55 & -0.0071 & -0.52 \\
\hline & Household has a lodgment & 0.003 & 1.00 & -0.0004 & -0.08 & $0.028 * *$ & 2.03 \\
\hline
\end{tabular}

Notes: The $t$-values reported are determined using the Huber-White test. ${ }^{* *}$ and ${ }^{* * *}$ show significance at the $5 \%$ and $1 \%$ levels, respectively.

Table 3 shows the results of partial risk-sharing. From this table, we note that the coefficients of income and health expenditure $(\gamma$ and $\delta)$, on average, are not significant for most variables, except for non-food consumption. Note that partial risk-sharing only takes place for non-food consumption. Changes in the growth rate of average income seem to have a positive and significant effect on the growth rate of non-food consumption, for those who are not covered. This result can be explained by a lack of insurance rather than changes to household preference. This aligns with the results of Dercon and Krishnan (2000) and Gertler and Gruber (2002).

The growth rate of average health expenditure does not affect the growth rate of total consumption and, therefore, does not affect partial risk-sharing for non-covered households. Our assumption of the absence of risk-sharing is accepted for health expenditure.

The average income coefficients and the average health expenditure ( $\hat{\gamma} p$ and $\hat{\delta} p$ ), for covered households, are still not significant. There is no significant difference observed in the insurance level of average consumption between covered and non-covered households. The growth rate of health care expenditure has no effect on insurance consumption and, subsequently, no effect on household 
vulnerability to risk. Therefore, the partial risk-sharing hypothesis is rejected for covered households. The analysis, so far, has investigated whether risk-sharing exists among poor households who are covered and not yet covered by social security in Metlaoui.

Table 4 presents the various estimates of vulnerability to risk by considering the characteristics of each group of households. Columns 1-3 of the table show how some household characteristics correlate with consumption insurance for non-covered households. There are four groups. The coefficient estimates in the column of non-covered households, with a head of household that has a lower level of education, appears to be most vulnerable to risk. The coefficient for this sub-group was equal to 0.885 . This was the highest value among all the groups. Households aged 50 years or over were the second group most vulnerable to risk, with a coefficient of 0.829 , followed by households where the head of the household was a female (0.828), and, finally, those who do not have a house were the least vulnerable to income risks (0.802).

A higher $\beta$ coefficient means that the degree of consumption insurance decreases and, subsequently, vulnerability to risk increases. For non-covered households, vulnerability to risk was high. Low-educated households were the most vulnerable to risk, since they were the least recruited. Older households were in second place, as they have the highest level of health expenditure and they are in the age of retirement but do not have a source of repayment.

The coefficient of health expenditure was still not significant for the non-food consumption of those who have a lower education and those who have a house. For the first sub-group, $\beta^{\prime}$ was significantly negative (-0.07). Therefore, the non-food consumption of this household group was less vulnerable to health care shocks. It is possible that those with a lower education did not need the internet and luxury goods that are a component of non-food consumption.

For the second sub-group, $\beta^{\prime}$ was significantly positive $(-0.02)$, showing that non-food consumption is less vulnerable to health care shocks. These types of households likely have a lower sensitivity than other sub-groups because they do not have an additional load of housing (i.e., rent). Generally, for non-covered households, there is a lack of coverage against the risks of income and health expenditure.

Comparing the three other columns of Table 4, we find some interesting results regarding the effect of social security on covered households. Note that most of the coefficients were negative, suggesting that the presence of social protection enhanced insurance possibilities compared to households that were not yet covered. However, these differences were only statistically significant in some cases.

For covered people, significant reductions in vulnerability to income risk were observed for two characteristics: households with an education level less than primary school $\left(\beta_{\mathrm{T} \text { cons }}=-0.43\right.$, $\left.\beta_{\text {nonfood cons }}=-1.53\right)$ and households older than 50 years of age $\left(\beta_{\mathrm{T} \text { cons }}=-0.23\right)$. These two household categories are less confident in the social security system and generally adopt a pro-cyclical strategy of income smoothing.

For health expenditure shocks, we note that insurance has an effect on vulnerability for the two sub-groups mentioned above. We note that the coefficient $\beta^{\prime}$ is significantly negative ( $\beta^{\prime}$ T.cons $=-0.041$, $\beta_{\text {food cons }}^{\prime}=-0.039$ ). Social security (i.e., through the National Health Insurance Fund) is accompanied by a lower vulnerability to risk. This can be explained by the observation that when an economic agent is insured, their risk management behavior is influenced by the presence of insurance and, as a result, there is a decrease in risk exposure. Health care expenditure for the older age group is accompanied by compensation paid by the National Health Insurance Fund as this sub-group has a higher probability of being sick than other groups. Social security reduces vulnerability to health expenditure risk for these two groups.

For the households who have a lodgment, the coefficients of income and health expenditure $\left(\beta_{\mathrm{P}}\right.$ and $\left.\beta_{P}^{\prime}\right)$ were not significant for all variables. Social security had no impact on this sub-group, even though this criterion is important for the welfare of households. It is clear that the role of social security remains insufficient and that there are severe barriers to the access of banking services. 
Therefore, OLS estimates of complete risk-sharing suggest that the presence of social security does not have an impact on the degree of vulnerability to risk for covered households. Estimates of the effect of income and health care expenditure shocks on consumption by characteristics of the household suggest that there is heterogeneity in how insurance affects the vulnerability to risk of different sub-groups. It is clear that social security plays an important role in minimizing risk vulnerability for those covered by social security, but that this role remains insufficient for some risks.

The estimated marginal effects of shock variables (Equation (6)) on the probability of adopting specific responses are presented in the Table 5.

From Table 5, we note that there is no single strategy adopted by non-covered households in Metlaoui. In terms of lost items or furniture, the different strategies chosen by non-covered households to cope with this shock included selling animals, working more, receiving help from family, selling other items, and receiving help from the government. We note that for most of the shocks, the non-covered were more likely to sell animals and other items or receive help from the government. These self-insurance strategies are expensive and may endanger the future economic status of the non-covered household. 
Table 4. The effect of income and health care expenditures shocks on consumption by characteristics of the household.

\begin{tabular}{|c|c|c|c|c|c|c|c|c|c|c|c|c|c|}
\hline \multirow{3}{*}{ Characteristics } & \multirow{3}{*}{ Dependent Variables } & \multicolumn{6}{|c|}{ Not Covered } & \multicolumn{6}{|c|}{ Covered } \\
\hline & & \multicolumn{2}{|c|}{$\begin{array}{c}\ln \text { (Total } \\
\text { Consumption) }\end{array}$} & \multicolumn{2}{|c|}{$\begin{array}{c}\ln (\text { Food } \\
\text { Consumption) }\end{array}$} & \multicolumn{2}{|c|}{$\begin{array}{l}\text { Ln (Non-Food } \\
\text { Consumption) }\end{array}$} & \multicolumn{2}{|c|}{$\begin{array}{c}\ln \text { (Total } \\
\text { Consumption) }\end{array}$} & \multicolumn{2}{|c|}{$\begin{array}{c}\ln (\text { Food } \\
\text { Consumption) }\end{array}$} & \multicolumn{2}{|c|}{$\begin{array}{l}\text { Ln (Non-Food } \\
\text { Consumption }\end{array}$} \\
\hline & & Coefficient & $t$-Value & Coefficient & $t$-Value & Coefficient & $t$-Value & Coefficient & $t$-Value & Coefficient & $t$-Value & Coefficient & $t$-Value \\
\hline Household head is a female & $\begin{array}{c}\text { Income } \\
\text { Health care expenditure }\end{array}$ & $\begin{array}{l}0.828^{* * *} \\
-0.0086\end{array}$ & $\begin{array}{l}4.07 \\
-0.6\end{array}$ & $\begin{array}{c}0.345 \\
0.0075\end{array}$ & $\begin{array}{l}0.99 \\
0.39\end{array}$ & $\begin{array}{l}3.08^{* * *} \\
-0.075\end{array}$ & $\begin{array}{l}4.92 \\
-1.3\end{array}$ & $\begin{array}{c}0.147 \\
-0.011\end{array}$ & $\begin{array}{c}0.48 \\
-0.41\end{array}$ & $\begin{array}{c}0.613 \\
-0.006\end{array}$ & $\begin{array}{c}1.2 \\
-0.17\end{array}$ & $\begin{array}{l}-1.08 \\
-0.01\end{array}$ & $\begin{array}{l}-0.84 \\
-0.13\end{array}$ \\
\hline Older than 50 years of age & $\begin{array}{c}\text { Income } \\
\text { Health care expenditure }\end{array}$ & $\begin{array}{l}0.829^{* * *} \\
0.0153\end{array}$ & $\begin{array}{c}10.01 \\
1.68\end{array}$ & $\begin{array}{c}0.866^{* * *} \\
-0.003\end{array}$ & $\begin{array}{c}3.08 \\
-0.14 \\
\end{array}$ & $\begin{array}{c}1.243 * \\
0.052\end{array}$ & $\begin{array}{c}1.7 \\
1.05\end{array}$ & $\begin{array}{l}-0.23 \text { ** } \\
-0.041^{* *}\end{array}$ & $\begin{array}{l}-1.96 \\
-2.07\end{array}$ & $\begin{array}{l}-0.051 \\
-0.03\end{array}$ & $\begin{array}{l}-0.18 \\
-1.19 \\
\end{array}$ & $\begin{array}{l}-0.95 \\
-0.11 \\
\end{array}$ & $\begin{array}{l}-1.19 \\
-1.52 \\
\end{array}$ \\
\hline $\begin{array}{l}\text { Householder head: less than } \\
\text { primary education }\end{array}$ & $\begin{array}{c}\text { Income } \\
\text { Health care expenditure }\end{array}$ & $\begin{array}{c}0.885 * * * \\
-0.169\end{array}$ & $\begin{array}{c}7.32 \\
-1.27\end{array}$ & $\begin{array}{l}0.675 * * * \\
-0.0003\end{array}$ & $\begin{array}{c}3.56 \\
-0.03\end{array}$ & $\begin{array}{l}2.036^{* * *} \\
-0.07^{* * *}\end{array}$ & $\begin{array}{c}5.1 \\
-1.85\end{array}$ & $\begin{array}{c}-0.438^{* * * *} \\
-0.021\end{array}$ & $\begin{array}{l}-2.59 \\
-1.01\end{array}$ & $\begin{array}{l}-0.14 \\
-0.03 *\end{array}$ & $\begin{array}{l}-0.52 \\
-1.82\end{array}$ & $\begin{array}{c}-1.53 * * * \\
-0.023\end{array}$ & $\begin{array}{l}-2.97 \\
-0.34\end{array}$ \\
\hline Lodgment & $\begin{array}{c}\text { Income } \\
\text { Health care expenditure }\end{array}$ & $\begin{array}{l}0.802 * * * \\
-0.0086\end{array}$ & $\begin{array}{c}3.45 \\
-1.39\end{array}$ & $\begin{array}{l}0.55^{*} \\
0.004\end{array}$ & $\begin{array}{l}1.75 \\
0.29\end{array}$ & $\begin{array}{c}2.23 * \\
-0.02 *\end{array}$ & $\begin{array}{c}1.74 \\
-1.74\end{array}$ & $\begin{array}{l}-0.102 \\
0.02\end{array}$ & $\begin{array}{c}-0.49 \\
1.18\end{array}$ & $\begin{array}{l}-0.08 \\
0.03\end{array}$ & $\begin{array}{l}-0.27 \\
1.57\end{array}$ & $\begin{array}{c}0.44 \\
-0.077\end{array}$ & $\begin{array}{c}0.38 \\
-0.68\end{array}$ \\
\hline
\end{tabular}

Notes: The $t$-values reported are based on Huber White test. ${ }^{*},{ }^{* *},{ }^{* * *}$ : significance to the thresholds of $10 \%, 5 \%$ and $1 \%$ respectively.

Table 5. Results of household responses to shocks.

\begin{tabular}{|c|c|c|c|c|c|c|c|c|c|c|c|c|}
\hline \multirow{2}{*}{ Independent Variables } & \multicolumn{2}{|c|}{ Borrow Money } & \multicolumn{2}{|c|}{ Sale of Other Items } & \multicolumn{2}{|c|}{ Work More } & \multicolumn{2}{|c|}{ Receive Help from Family } & \multicolumn{2}{|c|}{ Sale of Animals } & \multicolumn{2}{|c|}{ Receive Help from Government } \\
\hline & Coefficient & $z$-Value & Coefficient & $z$-Value & Coefficient & $z$-Value & Coefficient & $z$-Value & Coefficient & $z$-Value & Coefficient & $z$-Value \\
\hline \multicolumn{13}{|c|}{ Not covered households $(\hat{\beta})$} \\
\hline Death, or loss of house & -0.0008 & -0.11 & 0.123 ** & 2.06 & -0.05 & -0.62 & -0.16 & -1.59 & 0.02 & 0.35 & $0.47^{*}$ & 1.71 \\
\hline Injury of a family member & 0.013 & 0.23 & $0.133 * * *$ & 2.66 & $-0.15^{* *}$ & -1.98 & 0.07 & 1.14 & 0.06 & 1.21 & 0.01 & 0.07 \\
\hline Loss of harvest & 0.057 & 0.92 & 0.09 & 1.40 & -0.01 & -0.23 & -0.066 & -0.8 & $0.098^{*}$ & 1.77 & -0.03 & -0.11 \\
\hline Loss of other items/furniture & -0.037 & -0.51 & $0.10^{*}$ & 1.85 & $-0.14 *$ & -1.75 & $0.182^{* * *}$ & 2.8 & $0.128^{* * *}$ & 2.57 & $0.41^{*}$ & 1.68 \\
\hline \multicolumn{13}{|c|}{ Covered households $(\hat{\beta} p)$} \\
\hline Death, or loss of house & 0.147 & 1.48 & -0.06 & -0.67 & -0.09 & -0.7 & $0.272^{* * *}$ & 2.05 & -0.14 & -1.23 & -0.51 & -1.06 \\
\hline Injury of a family member & $0.145^{*}$ & 1.96 & $-1.23 * * *$ & -2.88 & $0.16^{*}$ & 1.67 & -0.024 & -0.28 & -0.11 & -1.54 & 0.17 & 0.51 \\
\hline Loss of harvest & 0.05 & 0.58 & -0.15 & -1.55 & -0.02 & -0.23 & 0.068 & 0.6 & -0.092 & -1.15 & 0.28 & 0.67 \\
\hline Loss of other items/furniture & $0.167^{*}$ & 1.89 & $-0.19^{* *}$ & -2.08 & $0.2^{*}$ & 1.91 & $-0.36 * * *$ & -2.36 & -0.11 & -1.57 & -0.64 & -1.47 \\
\hline Head of household is female & -0.0008 & -0.11 & 0.123 ** & 2.06 & -0.05 & -0.62 & -0.16 & -1.59 & 0.02 & 0.35 & $0.47 *$ & 1.71 \\
\hline Age is over 50 years & 0.013 & 0.23 & $0.133 * * *$ & 2.66 & $-0.15^{* *}$ & -1.98 & 0.07 & 1.14 & 0.06 & 1.21 & 0.01 & 0.07 \\
\hline Education level is less than primary & 0.057 & 0.92 & 0.09 & 1.40 & -0.01 & -0.23 & -0.066 & -0.8 & $0.098 *$ & 1.77 & -0.03 & -0.11 \\
\hline Household has a lodgment & -0.037 & -0.51 & $0.10^{*}$ & 1.85 & -0.14 * & -1.75 & $0.182 * * *$ & 2.8 & $0.128^{* * *}$ & 2.57 & $0.41 *$ & 1.68 \\
\hline
\end{tabular}

Notes: All variable "shocks" are included in the regression. The shock coefficients mentioned are in terms of the marginal effect on the probability of the 'outcome' (dF/dx). ${ }^{*}{ }^{* *}$, and ${ }^{* * *}$ show significance at the $10 \%, 5 \%$, and $1 \%$ levels, respectively. 
For covered households, in the case of injury of a household member, they were more likely to borrow money. The coefficient for this variable was significant and positive (0.14), which implies that this shock has a positive impact on the probability of borrowing money. Covered households were also more likely to respond by working more, as shown by the coefficient of 0.16 , in an attempt to increase their income. Covered households were less likely to sell furniture and other items $\left(\beta_{p}=-1.23\right)$.

In addition, in response to a loss of furniture, covered households were less likely to receive help from family, as shown by a coefficient of -0.36 , as well as being less likely to sell other items $\left(\beta_{p}=-0.19\right)$. In contrast, they were more likely to work more (with a coefficient $\left.=0.2\right)$ and borrow money.

Therefore, following this analysis, we can note that covered households are less likely to choose to sell animals or other items and are more likely to try to improve their income to cope with these shocks. In contrast, non-covered households are more likely to opt to sell animals and other items and they are less likely to work more.

This section shows that covered households are less likely to sell items and animals in the case of health care risks (injury of a family member), than non-covered households. Hence, the poverty rate is high for non-covered households. In addition, these households use costly risk coping strategies to pay for medical care and for coping with the incidence of some shocks, which can increase the risk of ending up in, or being trapped in a state of, poverty.

Concerning the sensitivity of the results, Table 6 presents the estimates of the model given by Equation (3), considering the instrumental variables of income. The proposed instruments are shock variables. The results show that no coefficients are significant. The results can be explained by the fact that the instruments have a weak effect on income (Skoufias 2007). We call this a "waiting problem" because the instrumental variables were binary. It was observed, in addition, that the rate of positive responses $\left(Z_{i}=1\right)$ was very limited.

Table 6. The sensitivity of results.

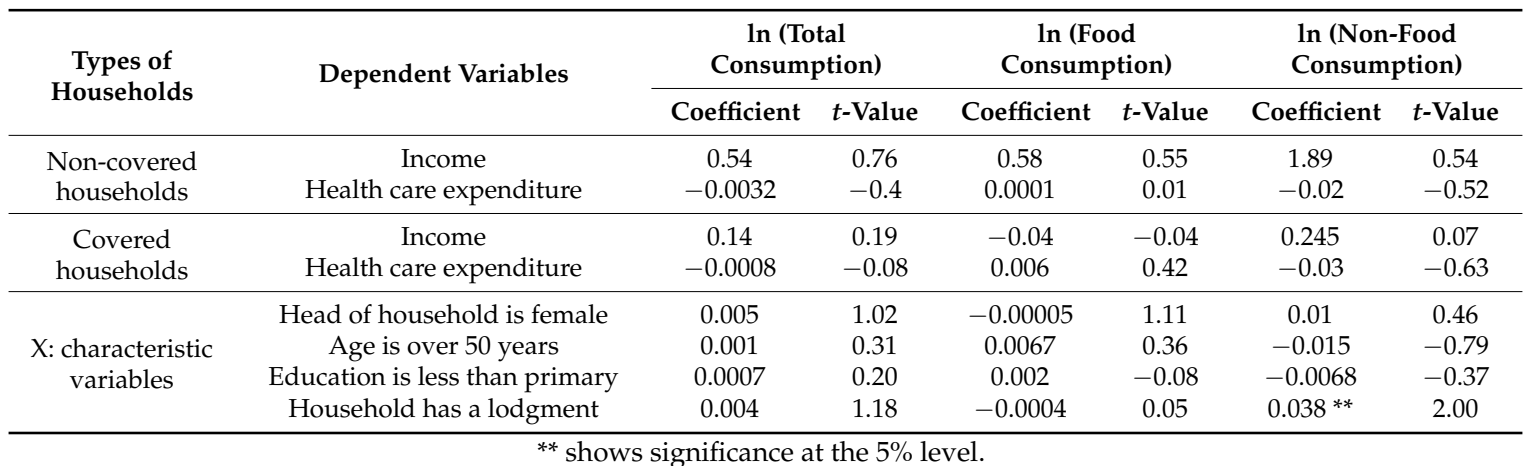

Table 7 presents the estimated coefficients of Equation (7), of shocks on the growth rate of total consumption, and the rate of food and non-food consumption.

Obviously, other shocks affect household consumption, as well as these two components. For non-covered households, estimates suggest that the impact of these shocks are not significant in the majority of cases, except for the shock of "injury of a household member" in terms of total consumption and food consumption. This shock has a negative effect only for food consumption.

The same shock has a positive effect on total consumption and food consumption for covered households. The "loss of items and furniture" shock is significant and negative for total consumption and non-food consumption. However, the other shocks have no effect. Hence, the growth of total, food, and non-food consumption is completely insured against other shocks.

These results may be due to differences in the reference period for the impact of the shock (6 months) and food consumption (last 7 days). Another possible explanation is that social security has 
a positive impact on household welfare, but its role remains insufficient to cover households against various shocks.

Table 7. The impact of shocks on household consumption.

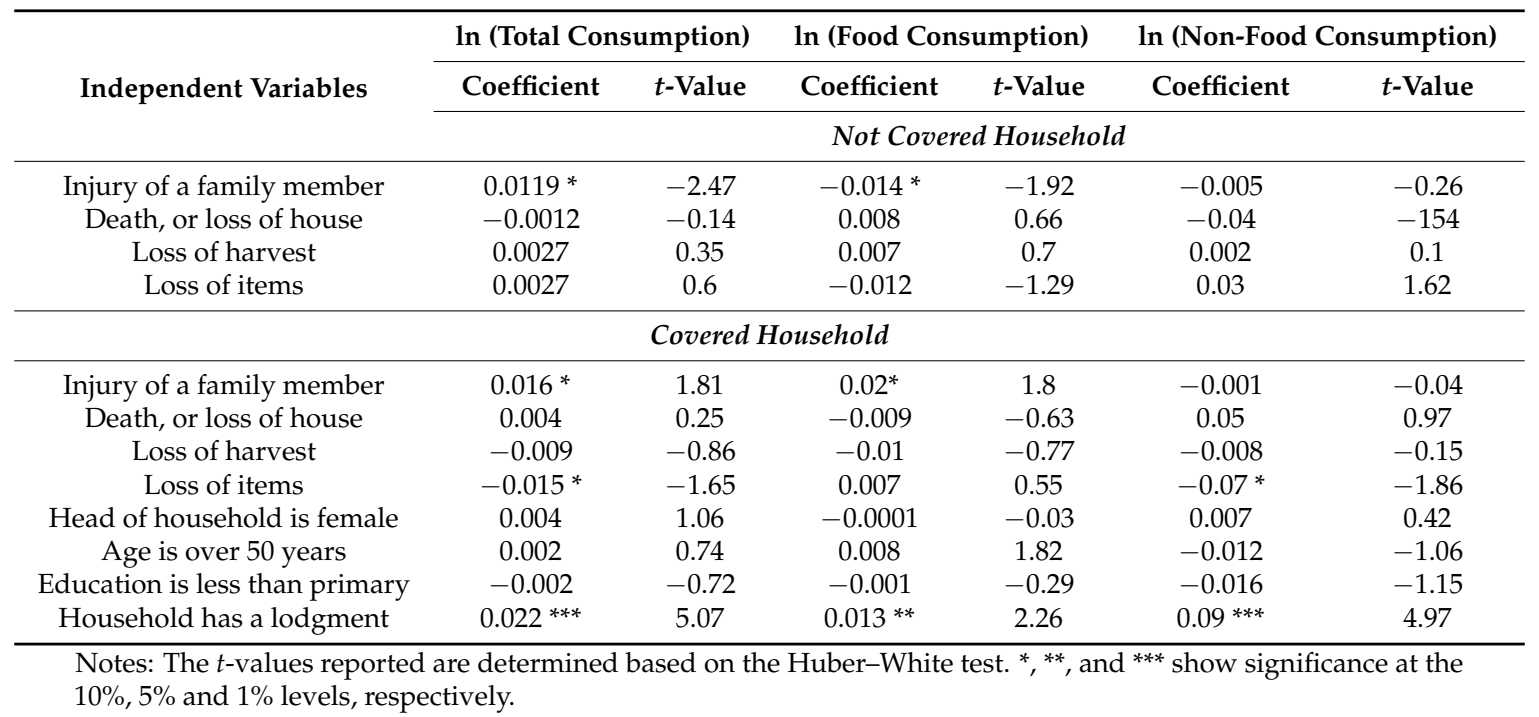

\section{Conclusions}

In this study, we examined the effect of social security schemes on poverty. First, a comparison of estimates between covered households and households not yet covered by social security suggest that risk-sharing is incomplete.

Estimates of the effect of income and health care expenditure shocks on consumption, by characteristics of the household, suggest that there is heterogeneity in how insurance affects the vulnerability to risks of different sub-groups. The results show that social security improves the possibility of coverage against risks and that there is heterogeneity in how insurance affects the vulnerability of households. Households eligible for social security are better able to protect their consumption from income fluctuations than their counterparts who are not covered.

Although in the last section we show that social security helps households choose the least costly strategies to face risks, its role is still insufficient, since covered households remain less confident regarding social security services and adopt self-insurance or income smoothing strategies. Pro-cyclical behavior against risks is usually found amongst those who are less educated and older, as they are most vulnerable to shocks, compared to other categories of poor households. It was found that a high percentage of poor people have health care expenditures that exceed their budget. However, non-covered households support these expenses without any source of compensation, which may exacerbate their situation and may even cause them to fall below the poverty line.

In addition, it appears that the presence of the National Health Insurance Fund, Social Security Fund, and the National Pension and Social Contingency Fund, induces households to use adjustments in their work more frequently than non-covered households, when facing risks.

Although the exercise of activity reduces the risk of poverty for employed households more than unemployed households, this is no longer an absolute protection. Therefore, it is clear that there is a close link between social security, employment, and poverty reduction. Social security schemes have a primary mission to reduce health care expenditure, which can be considered one of the first causes of poverty. Thus, social security contributes to the fight against poverty. This system is limited and requires more effort to choose agents that are eligible for social security. Social security in Metlaoui is important but it remains insufficient, especially for those who are not covered and are suffering as a result of heavy health care expenditure. It is also clear that coverage against poverty cannot be fully elucidated from this small sample, as there may be questionnaire limitations and some 
of the households surveyed may have hidden information or presented themselves as being in an unfavorable situation. In addition, some variables, such as family size, are not included in the analysis due to the problem of multicollinearity.

Author Contributions: Hasna Khemili collected the data and conceived and performed the experiments using the analysis tools. Both authors, Hasna Khemili and Mounir Belloumi, analyzed the data and wrote the paper.

Conflicts of Interest: The authors declare no conflict of interest.

\section{References}

Alderman, Harold, and Christina H. Paxson. 1992. Do the Poor Insure? A Synthesis of the Literature on Risk and Consumption in Developing Countries. Policy Research Working Papers, Agricultural Policies, WPS 1008. Washington: The World Bank.

Altug, Sumru, and Robert A. Miller. 1990. Household Choices in Equilibrium. Econometrica 58: 543-70. [CrossRef]

Amin, Sajeda, Ashok S. Rai, and Giorgio Topa. 2003. Does microcredit reach the poor and vulnerable? Evidence from northern Bangladesh. Journal of Development Economics 70: 59-82. [CrossRef]

Attanasio, Orazio, and Steven J. Davis. 1996. Relative Wage Movements and the Distribution of Consumption. Journal of Political Economy 104: 1227-62.

Attanasio, Orazio P., and Nicola Pavoni. 2011. Risk sharing in private information models with asset accumulation: Explaining the excess smoothness of consumption. Econometrica 79: 1027-68.

Coate, Stephen, and Martin Ravallion. 1993. Reciprocity without commitment: Characterization and performance of informal insurance arrangements. Journal of Development Economics 40: 1-24. [CrossRef]

Cochrane, John H. 1991. A simple test of consumption insurance. Journal of Political Economy 99: 957-76. [CrossRef]

Deaton, Angus. 1992. Saving and income smoothing in Cote d'Ivoire. Journal of African 1: 1-24.

Deaton, Angus. 1997. The Analysis of Household Surveys: A Micro-Econometric Approach to Development Policy. Baltimore: The Johns Hopkins University Press, pp. 335-93.

Dekker, Marleen. 2004. Sustainability and resourcefulness: Support networks in times of stress. World Development 32: 1735-52. [CrossRef]

Dekker, Marleen, and Annegien Wilms. 2010. Health Insurance and Other Risk-Coping Strategies in Uganda: The Case of Micro Care Insurance Ltd. World Development 38: 369-78. [CrossRef]

Dercon, Stefan, and Pramila Krishnan. 2000. In sickness and in health: Risk sharing within households in rural Ethiopia. Journal of Political Economy 108: 688-727. [CrossRef]

Fafchamps, Marcel, and John Pender. 1997. Precautionary Saving, Credit Constraints, and Irreversible Investment: Theory and Evidence from Semi-Arid India. Journal of Business and Economic Statistics 15: 180-94. [CrossRef]

Fafchamps, Marcel, Christopher Udry, and Katherine Czukas. 1998. Drought and Saving in West Africa: Are Livestock a Buffer Stock? Journal of Development Economics 55: 273-305. [CrossRef]

Garcia-Verdu, Rodrigo. 2002. Evaluation of Conditional Income Support Programs: The Case of Mexico's Progress. Doctoral dissertation, University of Chicago, Chicago, IL, USA.

Gertler, Paul, and Jonathan Gruber. 2002. Insuring consumption against illness. American Economic Review 92: 51-76. [CrossRef] [PubMed]

Handa, Sudhanshu, Mari-Carmen Huerta, Raul Perez, and Beatriz Straffon. 2000. Poverty, Inequality, and 'SPILL-OVER' in Mexico's Education, Health, and Nutrition Program. Washington: International Food Policy Research Institute, pp. 1-40.

Hayashi, Fumio, Joseph Altonji, and Laurence Kotlikoff. 1996. Risk Sharing between and within Families. Econometrica 64: 261-94. [CrossRef]

Heckman, James J., Robert J. LaLonde, and Jeffrey A. Smith. 1999. The economics and econometrics of active labor market programs. In Handbook of Labor Economics. Edited by Ashenfelter, Orley and David Card. Amsterdam: Elsevier, vol. 3, pp. 1-73.

Holzmann, Robert, and Steen Jorgensen. 2000. Social Risk Management: A New Conceptual Framework for Social Protection and Beyond. Social Protection Discussion Paper No. 0006. Washington: The World Bank, pp. 529-56.

Jacoby, Hanan G., and Emmanuel Skoufias. 1997. Risk, financial markets, and human capital in a developing country. Review of Economic Studies 64: 311-35. [CrossRef] 
Jacoby, Hanan G., and Emmanuel Skoufias. 1998. Testing theories of consumption behavior using information on aggregate shocks: Income seasonality and rainfall in rural India. American Journal of Agricultural Economics 80: 1-14. [CrossRef]

Kochar, Anjini. 1998. Smoothing consumption by smoothing income: Hours-of-work responses to idiosyncratic agricultural shocks in rural India. The Review of Economics and Statistics 81: 50-61. [CrossRef]

Kruse, Agneta, and Ann-Charlotte Ståhlberg. 2013. Welfare Economics. Theory, Empirical Results and the Swedish Experience. Lund: Studentlitteratur.

Leliveld, André. 2006. Poverty Trap or Safety Net? Dynamics in Social Security Arrangements in Ugandan Rural Economies. Paper presented at the Conference "The End of Poverty in Africa"? African Studies Centre, Leiden, The Netherlands, March 16.

Lim, Youngjae, and Robert M. Townsend. 1998. General Equilibrium Models of Financial Systems: Theory and Measurement in Village economies. Review of Economic Dynamics 1: 58-118. [CrossRef]

Mace, Barbara. 1991. Full insurance in the presence of aggregate uncertainty. Journal of Political Economy 99: 28-56. [CrossRef]

Morduch, Jonathan. 1994. Poverty and vulnerability. American Economic Review Papers and Proceedings 84: 221-25.

Nelson, Julie A. 1994. On testing for full insurance using consumer expenditure survey data. Journal of Political Economy 102: 384-94. [CrossRef]

Perry, Guillermo E., Omar S. Arias, J. Humberto López, William F. Maloney, and Luis Servén. 2006. Poverty Reduction and Growth: Virtuous and Vicious Circles. Washington: The World Bank, pp. 1-238.

Ravallion, Martin, and Shubham Chaudhuri. 1997. Risk and insurance in village India: Comment. Econometrica 65: 171-84. [CrossRef]

Rosenzweig, Mark R., and Kenneth I. Wolpin. 1993. Credit market constraints, consumption smoothing and the accumulation of durable production assets in low-income countries: Investments in Bullocks in India. Journal of Political Economy 101: 223-44. [CrossRef]

Samphantharak, Krislert, and Robert Townsend. 2017. Risk and Return in Village Economies. NBER Working Paper No. 19738. Cambridge: National Bureau of Economic Research.

Scheil-Adlung, Xenia, Guy Carrin, Johannes Juetting, and Ke Xu. 2006. What Is the Impact of Social Health Protection on Access to Health Care, Health Expenditure and Impoverishment? A Comparative Analysis of Three African Countries. ESS Working Paper No. 24. Geneva: International Labor Office, pp. 1-18.

Skoufias, Emmanuel. 2007. Poverty alleviation and consumption insurance: Evidence from PROGRESSA in Mexico. The Journal of Socio-Economics 36: 630-49. [CrossRef]

Townsend, Robert. 1994. Risk and insurance in village India. Econometrica 62: 539-91. [CrossRef]

Townsend, Robert. 1995. Consumption insurance: An evaluation of risk-bearing systems in low-income economies. Journal of Economic Perspectives 2: 83-102. [CrossRef]

Young, Pamela, P. Mukwana, and E. Kiyaga. 2006. Micro-Insurance Exploring Ways to Assess Its Impact. Washington: Microfinance Opportunities/IRIS, pp. 1-21.

(C) 2018 by the authors. Licensee MDPI, Basel, Switzerland. This article is an open access article distributed under the terms and conditions of the Creative Commons Attribution (CC BY) license (http:/ / creativecommons.org/licenses/by/4.0/). 